\title{
Coastline Change Modelling Induced by Climate Change Using Geospatial Techniques in Togo (West Africa)
}

\author{
Yawo Konko1,2*, Appollonia Okhimambe², Pouwèréou Nimon ${ }^{3}$, Jerry Asaana ${ }^{2,4}$, \\ Jean Paul Rudant ${ }^{5}$, Kouami Kokou ${ }^{6}$ \\ ${ }^{1}$ National Environmental Observatory, National Agency of Environment Management, Lome, Togo \\ ${ }^{2}$ West African Science Service Centre on Climate Change and Adapted Land Use, Federal University of Technology, Minna, Nigeria \\ ${ }^{3}$ National Meteorological Service, Lome, Togo \\ ${ }^{4}$ Department of Civil Engineering, Bolgatanga Technical University, Bolgatanga, Ghana \\ ${ }^{5}$ LASTIG, Gustave Eiffel University, ENSG, IGN, Champs-sur-Marne, France \\ ${ }^{6}$ Laboratory of Forest Research, Faculty of Sciences, University of Lome, Lome, Togo \\ Email: *konkoyawo2@gmail.com
}

How to cite this paper: Konko, Y., Okhimambe, A., Nimon, P., Asaana, J., Rudant, J.P. and Kokou, K. (2020) Coastline Change Modelling Induced by Climate Change Using Geospatial Techniques in Togo (West Africa). Advances in Remote Sensing, 9, 85-100. https://doi.org/10.4236/ars.2020.92005

Received: March 18, 2020

Accepted: June 5, 2020

Published: June 8, 2020

Copyright $\odot 2020$ by author(s) and Scientific Research Publishing Inc. This work is licensed under the Creative Commons Attribution International License (CC BY 4.0).

http://creativecommons.org/licenses/by/4.0/

\section{Open Access}

\begin{abstract}
Climate change is a major concern of humanity. One of the consequences of climate change is global warming causing melting glaciers, rising sea levels and shoreline regression. In Togo, the regression of shoreline leads to coastal erosion with significant damage on socio-economic infrastructures and human habitats. This research, basing on geospatial techniques, focuses on coastal erosion monitoring from 1988 to 2018 in Togo. It is interested in the extraction of shoreline and in the analysis of change. Various satellite images indexes have been developed for shoreline extraction but the major scientific problem concerns the precision of the different classification algorithms methods used for the extraction of the shoreline from these water index. This study used NDWI index from multisource satellite images. It assesses the performance of Otsu threshold segmentation, Iso Cluster Unsupervised Classification and Support Vector Machine (SVM) Supervised Classification methods for the extraction of the shoreline on NDWI index. The topographic morphology such as linear and non-linear coastal surfaces have been considered. The estimation of the rates of change of the shoreline was performed using the statistical linear regression method (LRR). The results revealed that the SVM Supervised Classification method showed good performance on linear and non-linear coastal surface than the other methods. For the kinematics of the shoreline, the southwest of the Togolese coast has an average erosion rate ranging from 2.49 to $5.07 \mathrm{~m}$ per year. The results obtained will serve as decision-making support tools for the design and implementation of appropriate adaptations
\end{abstract}


plans to avoid the immersion of the asphalt road by sea, displacement of population and disturbance of human habitats.

\section{Keywords}

Coastal Erosion, Landsat Images, NDWI, Remote Sensing, Sentinel Images, Shoreline, SVM

\section{Introduction}

Climate change and its effects are of global concern and has become an active area of research for scientists [1]. One of the consequences of climate change is global warming causing melting glaciers, rising sea levels and shoreline regression [2]. A shoreline is the line of contact between land and a sea [3]. The regression of shoreline leads to coastal erosion with significant damage on socio-economic infrastructure and natural ecosystem [4] [5].

The West African coast is one of the areas severely affected by coastal erosion phenomena [6]. Of particular concern is the Togolese coast. Due to its configuration, the Togolese coast faces many challenges such as urban expansion and coastal erosion. The recent research of Konko et al. (2018) [2] in the East of the Togo coast showed that, the shoreline experienced an average recession ranging from 1.66 to $5.25 \mathrm{~m}$ per year while the urban area increases from 7.84 ha per year. Predictions based on those averages rate showed that the barrier beach with its residential areas whose the local population estimated at 82.724 inhabitants are exposed to a continual risk of inundation by shoreline regression which may affect more than $7 \%$ of its surface area by the 2070s. The inundation of the barrier beach could increase damage on socio-economics structures, human beings and rural exodus phenomenon.

Although the recent research of Konko et al. (2018) [2] links coastal erosion phenomenon to climate change and provides decision-making support tools for the implementation of appropriate adaptation plans in the East of the Togo coast, the data on the shoreline regression in the west part of the coast are lacking. According to Blivi and Adjoussi (2004) [7], the western part of the Togolese coast experienced coastal erosion phenomenon leading important damages. The lack of recent statistics data on the evolution of coastal erosion in this part of the coast does not allow predictions as well as the implementation of adaptation and mitigation measures.

Monitoring of shoreline in the whole of the Togolese coast is fundamental for planning, defining of hazard zones, and predicting of erosion. The present study, based on remote sensing techniques, is part of this perspective and focuses on the western part of the Togolese coast.

Remote sensing provides new technological advantages in costal monitoring research [8] and gives a big opportunity to obtain reliable shoreline information. Tools including satellite images are the preferred means for discrimination and 
monitoring of landscape features [9] [10].

Various water index methods from satellite imagery to improve the discrimination of aquatic and terrestrial areas in coastal zone have been developed such as Normalized difference water index (NDWI) and modified normalized difference water index.

Although the water index of satellite images allow a discrimination of terrestrial and aquatic areas, the major scientific problem concerns the precision of the different classification algorithms used for the extraction of the shoreline from these water index.

The techniques of image processing can provide reliable solutions for extraction shoreline issues. Some methods have been proposed. Support Vector Machine (SVM) [2] [11], Iterative Self Organized Data Analysis (ISODATA) [12], thresholding and morphological filtering [13], Random forest method [14], object-oriented fuzzy classification approaches [15], mean-shift segmentation [16] and genetic algorithm based methods [17] can be counted as mainly used methods for shoreline extraction.

In order to use the most suitable method for shoreline extraction from NDWI index commonly used, this study based in the west coast part of Togo, firstly, assesses the performance of Otsu threshold segmentation method, Iso Cluster Unsupervised Classification method and SVM Supervised Classification method for the extraction of the shoreline on linear and non-linear coastal surfaces (topographic morphology). Secondly, the study focused on the kinematics of the shoreline from 1988 to 2018.

\section{Materials and Methods}

\subsection{Study Area}

This study was conducted in the west of the Togolese coast, located in west part of the transboundary biosphere reserve of the Mono [18]. It is bounded between the latitudes $6^{\circ} 5^{\prime} 55.045^{\prime \prime}$ and $6^{\circ} 11^{\prime} 34.668^{\prime \prime}$ North and the longitudes $1^{\circ} 11^{\prime} 33.347^{\prime \prime}$ and $1^{\circ} 23^{\prime} 4.636^{\prime \prime}$ East (Figure 1). The study area is part of the coastal sedimentary basin of southern Togo which has a Guinean subequatorial climate characterized by four seasons, namely a long dry season from November to mid-March, a long rain season from mid-March to mid-July, a short dry season from August to September and a short rain season from October to November [19] [20]. Precipitations in the area are very irregular, ranging from 1000 to $1400 \mathrm{~mm} / \mathrm{year}$. The mean temperature is generally high, about $27^{\circ} \mathrm{C}$. The geology of the coastal sedimentary basin consists of three main aquifer horizons, namely Upper Cretaceous, Paleocene and Continental Terminal aquifers [2]. The main economic activities of residents are business and transport.

\subsection{Data Used}

The data used in this study was downloaded from

Landsat (https://landsat.usgs.gov/) and Sentinel (https://sentinel.esa.int/) platforms. 


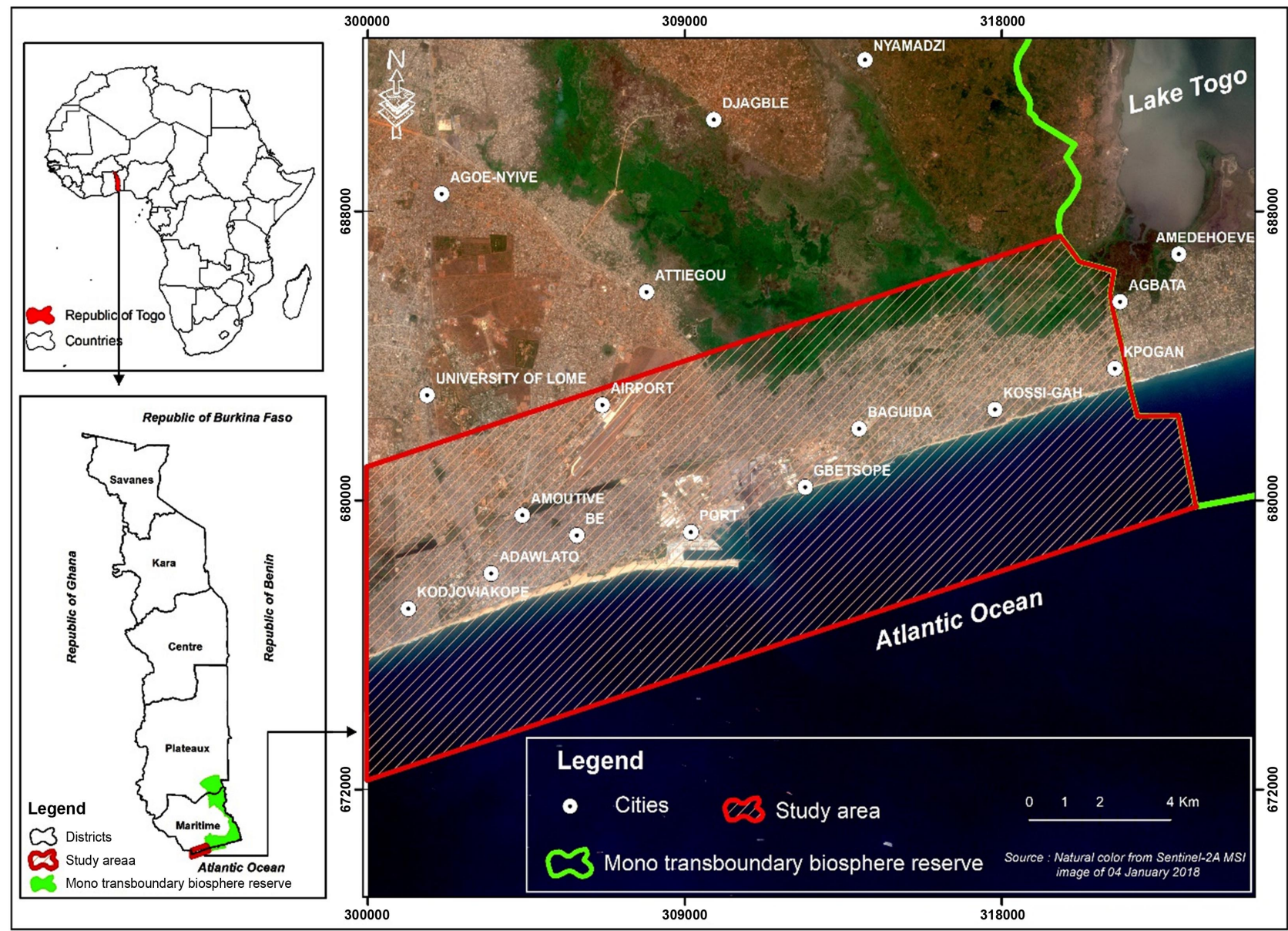

Figure 1. Map of West Togolese Coast with sentinel-2 image data.

The satellite images come from different sensors, including Thematic Mapper (TM), Enhanced Thematic Mapper Plus (ETM+) and Multi Spectral Instrument (MSI) respectively. TM, ETM+ and MSI measures the Earth's reflected. The breakdown of images is as follows: TM image of 12 February 1988 at 09:34:08 am, ETM+ image of 13 December 2000 at 09:59:54 am, MSI image of 04 January 2018 at 11:18:13 am. The dates were chosen in the long dry season in order to use images that were sensed in similar conditions and similar time for a coherent data analysis. TM and ETM+ images were collected on 192/056 (Path/Row) with a spatial resolution of $30 \mathrm{~m}$. MSI images were collected on T_31NCH Tile Number field. MSI images had a spatial resolution ranging from 10 to $60 \mathrm{~m}$. Apart from differences in resolution between the three sensors; there are also differences in bands. In fact, TM consists of seven bands. ETM+ has a pan-chromatic band in addition to those of TM. MSI has 13 bands: the $10 \mathrm{~m}$ bands include three RGB bands and a near-infrared band, the $20 \mathrm{~m}$ bands include four narrow visible near-infrared (VNIR) bands and two wider shortwave-infrared bands, and the $60 \mathrm{~m}$ bands are associated with cloud screening, atmospheric correction, and cirrus detection. Landsat TM and ETM+ consist of a thermal band, while Sentinel-2 MSI does not. 
The national topographic data of 2013 provided by the Japanese International Cooperation Agency (JICA) at a scale of 1/50,000 (Sheet NB-31-XIV-1b Baguida; Sheet NB-31-XIV-1a Lome), aerial photograph acquired on January 2018 and the fields data had been used as reference data.

\subsection{Images Pre-Processing}

All the optical images were pre-processed using the ENVI software. Firstly, the images were geo-referenced using GPS field surveys and JICA topographic data, under the UTM projection, according to the World Geodetic System, WGS 84, UTM 31North. Subsequently, pretreatments focused on radiometric correction, resampling and geometric correction operations. The radiometric correction operation allowed to reduce the atmospheric effects: The at-sensor radiance (digital number, ND) values were converted to surface reflectance with the FLAASH model [21]. In order to unify the spatial resolution of Landsat and Sentinel-2A images, the Near Infrared (NIR) band and the Green band of TM/ETM+ and MSI images from 1988, 2000 and 2018 were resampled to $15 \mathrm{~m}$ by the nearest neighborhood resampling method. The geometric correction is to remove geometric distortion. Image-to-image registration method in ENVI software was applied for the geometric correction of the Landsat and Sentinel-2A images. The Sentinel-2A MSI image from 2018 was used as the reference for the other images.

Various water index methods to improve the discrimination of aquatic and terrestrial areas from satellite imagery have been developed: Normalized difference water index [22], modified normalized difference water index [21], etc. In this study, the spectral water index based on normalized difference water index commonly used, namely, NDWI is used because of its efficiency and convenience [21]. NDWI is computed according to the Equation (1) where NIR refers to the Near infrared band (for the MSI images, NIR corresponds to Band 8 while for TM and ETM+ images, NIR corresponds to Band 4). Green refers to the Green band (for the MSI images, Green corresponds to Band 3 while for TM images and ETM+, Green corresponds to Band 2).

NDWI seeks to maximize reflectance of water using green wave-lengths, minimize the low reflectance of NIR by water features and finally, take advantage of the high reflectance of NIR by both the vegetation and the soil. Typically, as results, water has positive values while soil and vegetation have either nil or negative value.

$$
\mathrm{NDWI}=\frac{\text { Green }- \text { NIR }}{\text { Green }+ \text { NIR }}
$$

\subsection{Shoreline Extraction Methods}

The shoreline is the line of contact between land and a sea [3]. Various methods for shoreline extraction and change detection from satellite images have developed: Manual method, image enhancement, write function memory insertion, density 
slice using single or multiple bands and multi-spectral classification, multi-date data classification and comparison of two independent land cover classifications, images digitization, both supervised and unsupervised are the most common change detection techniques [2] [3] [23] [24] [25]. In addition, several image-processing algorithms such as pre-segmentation, segmentation and post-segmentation have been used for automatic extraction of the shoreline from satellite images [26].

The NDWI indices of satellite images allow a discrimination of terrestrial and aquatic areas but the major scientific problem concerns the performance or precision of the different classification methods used for the extraction of the shoreline from these water index. For that, this study explores the performances of three distinct methods commonly used in order to define the most suitable method for shoreline extraction on NDWI indices. The three methods are: Otsu threshold segmentation, Iso Cluster Unsupervised Classification and SVM supervised Classification methods.

The JICA data, aerial photograph acquired on January 2018 and the fields data had been used as reference data for validation and comparison of the result of three algorithms (methods).

\subsubsection{Otsu Threshold Segmentation Method}

Otsu's method proposed by Otsu (1975) [27], is a dynamic method that has been successfully used to partition the input raster image into homogeneous land and water regions through minimizing the intra-class variance [28] [29] [30].

The Otsu threshold segmentation method is powerful and provides dynamic and variational thresholds based on different regions in different sectors [31]. It still remains one of the most referenced thresholding methods [32] [33]. The thresholding method sets the threshold value automatically according to the local characteristics to achieve a good separation between the land and sea water. It is based on discriminate analysis and uses the zeroth and the first-order cumulative moments of the histogram for calculating the value of the thresholding level.

\subsubsection{Iso Cluster Unsupervised Classification Method}

The Iso Cluster Unsupervised Classification method has used to separate terrestrial and aquatic environments. This method performs unsupervised classification on a series of input raster bands and combines the functionalities of the Iso Cluster and Maximum Likelihood Classification tools. The Iso Cluster tool uses a modified iterative optimization clustering procedure, also known as the migrating means technique. The algorithm separates all cells into the user-specified number of distinct unimodal groups in the multidimensional space of the input bands. This tool is most often used in preparation for unsupervised classification [34] [35]. The algorithm used by the Maximum Likelihood Classification tool is based on two principles: The cells in each class sample in the multidimensional space being normally distributed and Bayes' theorem of decision-making. The tool considers both the variances and covariances of the class signatures when assigning each cell to one of the classes represented in the signature file. 


\subsubsection{The SVM Supervised Classification Method}

The SVM Supervised Classification method has been successfully used to separate terrestrial and aquatic areas [2]. SVM is a supervised non-parametric statistical learning technique. In general, it is based on the search for a hyperplane making it possible to separate observations while maximizing the margin (the distance from the point closest to the hyperplane) [36]. Vapnik (1982) developed the original formulation of the algorithm [37]. This algorithm has the ability to provide good classification results even when the number of training samples for region of interest (ROI) is low, which is a fairly recurrent constraint in applications of remote sensing. SVM also has the ability to minimize the risk of classification error even without prior knowledge on data distribution. Its performance of separating pixel is often higher than other traditional classifiers such as the maximum likelihood algorithm [36].

\subsection{Shoreline Kinematics}

In order to allow a better knowledge of the human habitats affected by coastal erosion phenomenon, the coast was subdivided into eight (8) rectangular sectors of about $3.25 \times 3 \mathrm{~km}$ (Figure 2). Although these sectors do not represent any natural or administrative boundary, they serve for sensitization, communication and decision making in many coastal human habitats. Indeed, it easier to indicate where changes occur so that action can be taken according to these sectors.

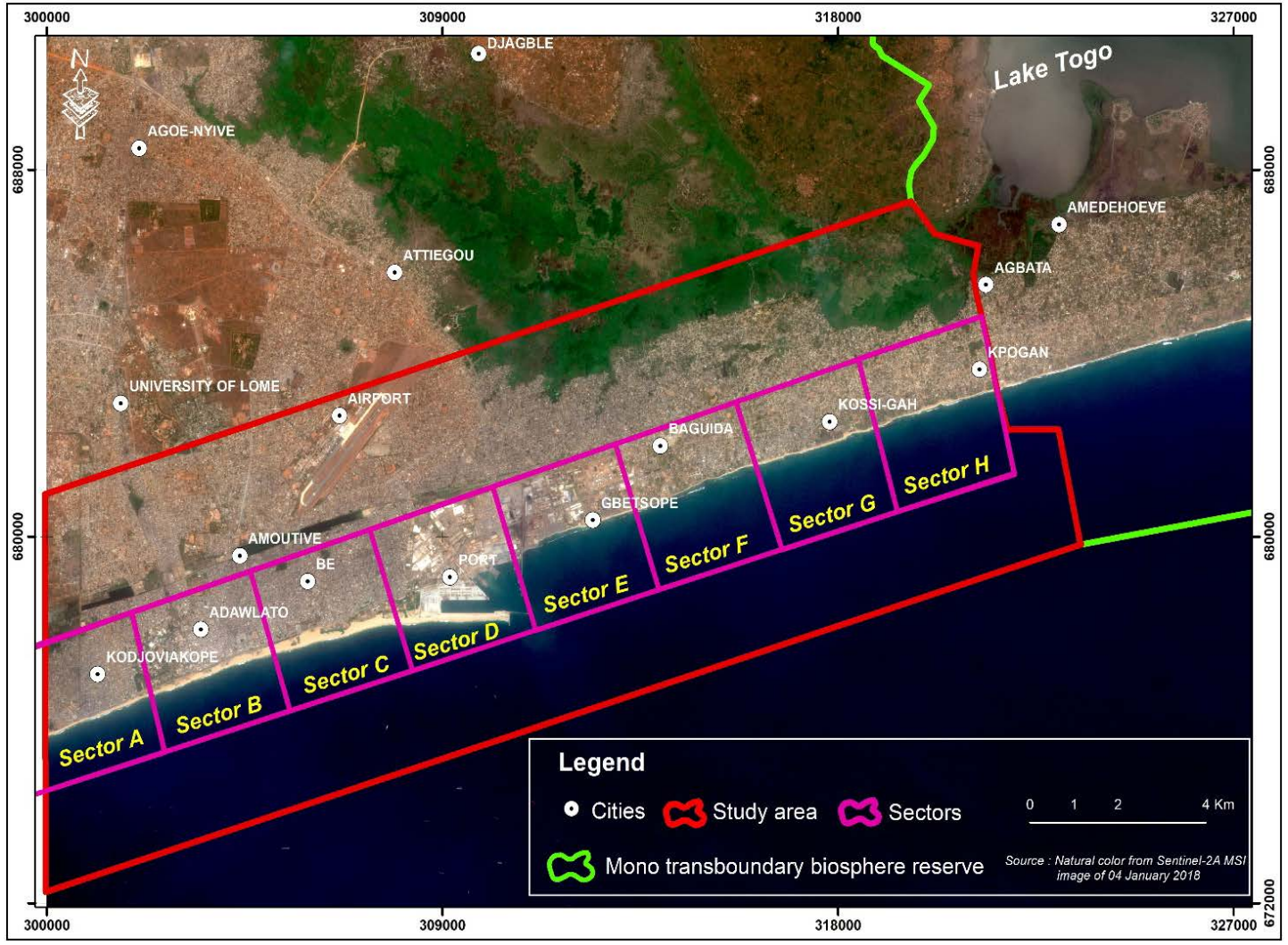

Figure 2. Map of coast subdivided into eight equal sectors on sentinel-2 Satellite image. 
Shoreline kinematics is evaluated by the dedicated Digital Shoreline Analysis System (DSAS) extension of ArcGIS [38]. DSAS extension requires the integration of shoreline shapefile within a geodatabase and the digitization of an imaginary baseline from which DSAS creates perpendicular transects to the lines to be compared. For this study, 590 transects were created. A conventional step of $50 \mathrm{~m}$ measurements is used between $500 \mathrm{~m}$ long transects.

The estimation of the rates of variation of the shoreline is performed by the linear regression (LRR) method. This method was used because of the multi-temporal image data. A LRR method of change statistic is determined by fitting a least-squares regression line to all shoreline points for a particular transect. It allows highlighting the evolutionary trend over time [2] [38] [39] [40].

\section{Results and Discussions}

\subsection{Comparison of the Performance of the Three Methods on Linear Surfaces}

The performances of Otsu threshold segmentation method, Iso Cluster Unsupervised Classification method and SVM Supervised Classification method for the extraction of the shoreline from the NDWI indices are shown in Figure 3. As shown on the NDWI indices of the MSI images, the three methods show good performance for the extraction of the shoreline (Figures 3(b)-(d)). On the other hand, the NDWI indices of the ETM + images, Otsu threshold segmentation shows better performances followed by SVM Supervised Classification and Iso Cluster Unsupervised Classification (Figures 3(f)-(h)). For the NDWI indices of TM images, although Otsu threshold segmentation and SVM Supervised Classification show better performance, Iso Cluster Unsupervised Classification has a tendency which is substantially the same (Figure 3(j)-(1)). Some research using Otsu threshold segmentation and SVM Supervised Classification have also concluded that they are efficient [2] [21].

\begin{tabular}{|c|c|c|c|c|}
\hline & NDWI Index & $\begin{array}{l}\text { Otsu threshold } \\
\text { segmentation }\end{array}$ & $\begin{array}{c}\text { Iso Cluster Unsupervised } \\
\text { Classification }\end{array}$ & $\begin{array}{c}\text { SVM Supervised } \\
\text { Classification }\end{array}$ \\
\hline $\begin{array}{l}\text { MSI } \\
\text { image }\end{array}$ & & & & \\
\hline & (a) & (b) & (c) & (d) \\
\hline $\begin{array}{l}\text { ETM+ } \\
\text { image }\end{array}$ & & & & \\
\hline & (e) & (f) & (g) & (h) \\
\hline $\begin{array}{l}\text { TM } \\
\text { image }\end{array}$ & & & & \\
\hline & (i) & (j) & (k) & (1) \\
\hline
\end{tabular}

Figure 3. Overview of the performance of the three methods for shoreline extraction on linear coastal surface. 


\subsection{Comparison of the Performance of the Three Methods on Non-Linear Surfaces}

The performances of Otsu threshold segmentation, Iso Cluster Unsupervised Classification and SVM Supervised Classification methods for the extraction of the shoreline on non-linear surfaces from NDWI indices are represented in Figure 4. It can be observed on the NDWI indices of the MSI images, that SVM Supervised Classification (Figure 4(d)) and Iso Cluster Unsupervised Classification (Figure 4(c)) show good performance compared to Otsu threshold segmentation (Figure 4(b)).

The same observations were experienced on the NDWI indices of the ETM + and TM images (Figures 4(f)-(h); Figures 4(j)-(1)). However, with regard to the comparison of SVM Supervised Classification and Iso Cluster Unsupervised Classification methods, the interpretation does not allow any conclusion. Additional statistical analyzes could help to judge the performance of these two algorithms on non-linear surfaces.

According Noumonvi et al. (2017) [41] SVM Supervised Classification is efficient in classifying complex landscapes and producing good results. It also performs better compared to many other satellite image classification methods. SVM Supervised Classification is a statistical learning classification technique. SVM Supervised Classification decisions focuses classification decisions on the boundary between classes and not on mean and variances of the classes.

\begin{tabular}{|c|c|c|c|c|}
\hline & NDWI Index & $\begin{array}{c}\text { Otsu threshold } \\
\text { segmentation }\end{array}$ & $\begin{array}{c}\text { Iso Cluster Unsupervised } \\
\text { Classification }\end{array}$ & $\begin{array}{c}\text { SVM supervised } \\
\text { Classification }\end{array}$ \\
\hline $\begin{array}{l}\text { MSI } \\
\text { image }\end{array}$ & & & & \\
\hline & (a) & (b) & (c) & (d) \\
\hline $\begin{array}{l}\text { ETM } \\
+ \\
\text { image }\end{array}$ & & & & \\
\hline & (e) & (f) & (g) & (h) \\
\hline $\begin{array}{l}\text { TM } \\
\text { image }\end{array}$ & & & & \\
\hline & (i) & (j) & (k) & (1) \\
\hline
\end{tabular}

Figure 4. Overview of the performance of the three methods for shoreline extraction on non-linear coastal surface.

\subsection{Method Used for Shoreline Extraction}

In the extraction of the shoreline from the NDWI indices of the MSI images which have good spatial resolution $(10 \mathrm{~m})$, the three methods showed good results on the linear surfaces. On the other hand, on the low spatial resolution images (ETM + and TM), SVM Supervised Classification and Otsu threshold seg- 
mentation showed a good performance for the discrimination of terrestrial and aquatic surfaces compared to Iso Cluster Unsupervised Classification.

On non-linear coastal surfaces, SVM Supervised Classification and Iso Cluster Unsupervised Classification showed good performance on the NDWI indices of MSI, ETM + and TM images compared to Otsu threshold segmentation.

For this study, SVM Supervised Classification method is chosen because of its good performance on the NDWI indices of MSI, ETM + and TM images on linear and non-linear surfaces. This method also produced good result in other research [2] [11].

\subsection{Kinematics of the Shoreline}

The analysis indicates that over time, the shoreline changed substantially by sector (Figure 5). These variations are expressed in the first place by erosion phenomena. An in-depth analysis of the changes using the LRR method allowed to draw Table 1. A positive evolution rate means an accretion whereas a negative rate represents an erosion. It follows from Table 1 and Figure 5 that the shoreline had generally experienced erosion with sector $\mathrm{C}$ and D had experiencing more accretion phenomena. The average erosion rate is ranging from 2.49 to $5.07 \mathrm{~m} /$ year. The lowest rate is observed in sector A towards Kodjoviakopé locality while the highest rate is observed in the sector $\mathrm{H}$ towards Kpogan locality.

However, this regression observed on the Togolese shoreline is lower than the results of Blivi and Adjoussi (2004) [7], which showed a regression of the shoreline ranging from 5 to $10 \mathrm{~m} /$ year. This discrepancy could be explained by the difference in the methodological approachs. In this study, the shoreline is extracted from satellite images (Landsat TM, ETM+ and Sentinel-2A MSI) by using SVM supervised classification method, and the kinematics are evaluated using the statistical LRR method. In a previous study Blivi and Adjoussi (2004) [7], using Landsat image analysis (MSS and TM), the methods of shoreline extraction and calculation of the kinematics were not clearly defined.

Although the lowest erosion rate is observed in sector A, the erosion process is very advanced in this sector and the sea is near to asphalt road. Appropriate measures of adaptation must be taken in this sector to avoid the immersion of the road by sea. This will have negative consequences on human habitats. Indeed, this road plays an important role in the transit of merchandises between Lome, the Togolese capital, and Ghana the neighboring country.

Table 1. Evolution of the shoreline by the LRR method from 1988 to 2018.

\begin{tabular}{ccccccccc}
\hline & Sector A & Sector B & Sector C & Sector D & Sector E & Sector F & Sector G Sector H \\
\hline $\begin{array}{c}\text { Low value } \\
\text { (meter/year) }\end{array}$ & -3.88 & $-3.49+1.66$ & +1.85 & - & -4.16 & -6.64 & -5.46 & -6.35 \\
$\begin{array}{c}\text { High value } \\
\text { (meter/year) }\end{array}$ & -1.1 & $-1.01+2.83$ & +2.18 & - & -1.84 & -1.66 & -2.8 & -3.78 \\
$\begin{array}{c}\text { Average } \\
\text { (meter/year) }\end{array}$ & -2.49 & $-2.25+2.25$ & +2.06 & - & -3.00 & -4.15 & -4.13 & -5.07 \\
\hline
\end{tabular}




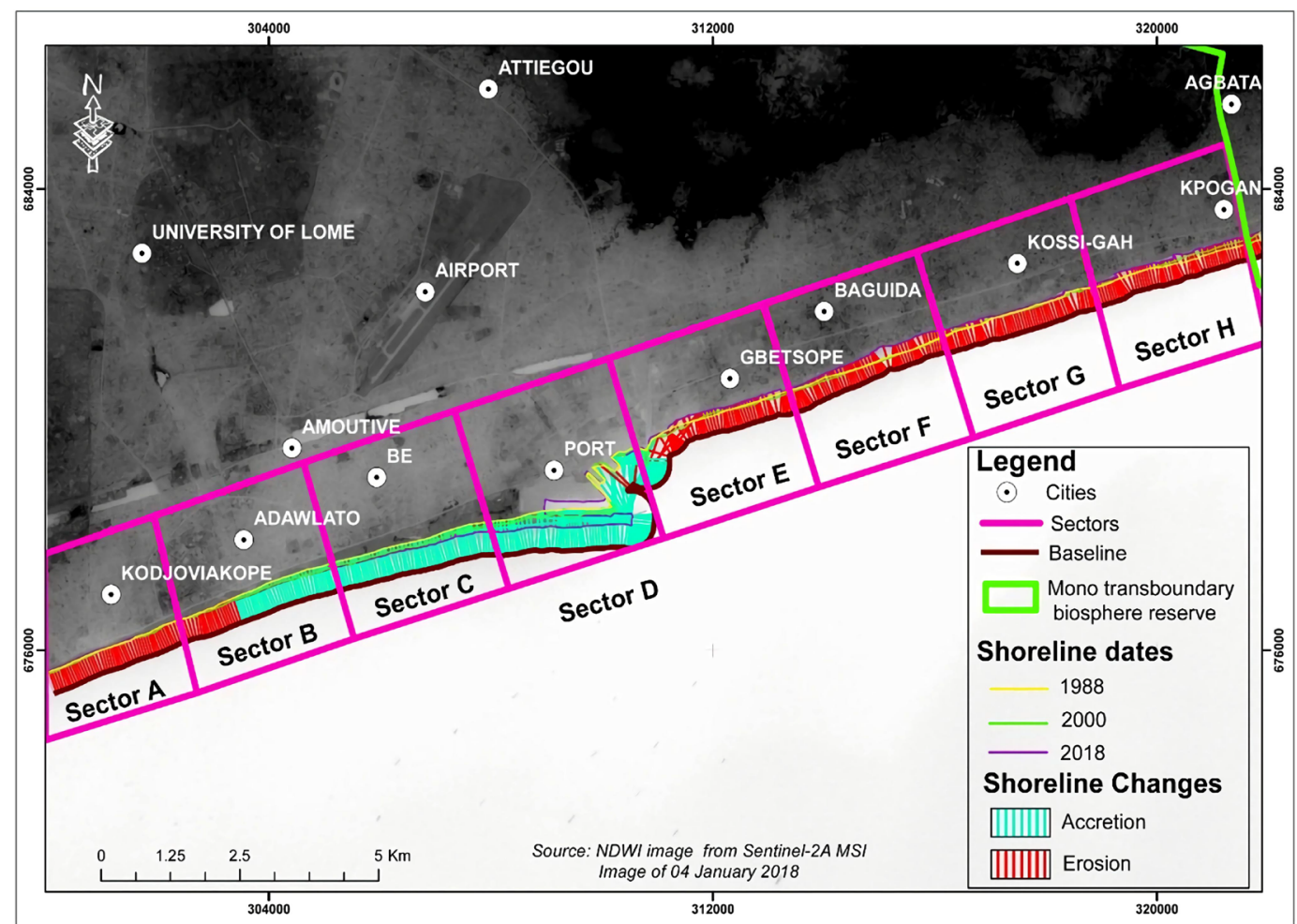

Figure 5. Map of shoreline changes with LRR method over the period 1988-2018.

The average high erosion rate observed in sector $\mathrm{H}(5.07 \mathrm{~m} /$ year $)$ is similar to the erosion rate provided by Konko et al. (2018) [2] in the neighbor area. These authors used the same method (SVM) for the extraction of the shoreline and found an average erosion rate of $5.20 \mathrm{~m} /$ year.

The sectors $\mathrm{E}, \mathrm{F}$ and $\mathrm{G}$ show an average erosion rate of $3.00 \mathrm{~m} / \mathrm{year}, 4.15$ $\mathrm{m} /$ year and $4.13 \mathrm{~m} /$ year respectively. The sector $\mathrm{B}$ presents a special case. It records both erosion and accretion phenomena. The area photograph of the coast in this sector is presented in Figure 6. In this aerial photograph, the sea is very close to the asphalt road where there is erosion in sector $\mathrm{B}$.

The sector $\mathrm{D}$ seem to record accretion phenomena. The sector $\mathrm{D}$ is a port area. The changes in the shoreline observed in sector D could therefore be linked to the installation of development infrastructures.

\section{Conclusions}

This study focused on coastal erosion monitoring in Togo from 1988 to 2018. Based on spatial remote sensing approach, this study firstly assesses the performance of Otsu threshold segmentation method, Iso Cluster Unsupervised Classification method and SVM Supervised Classification method for the extraction of the shoreline from the NDWI indices on linear and non-linear coastal surfaces. Secondly, this study focused on the kinematics of the shoreline.

The results reveal that the SVM Supervised Classification method showed good performance on linear and non-linear coastal surface than the other methods. 


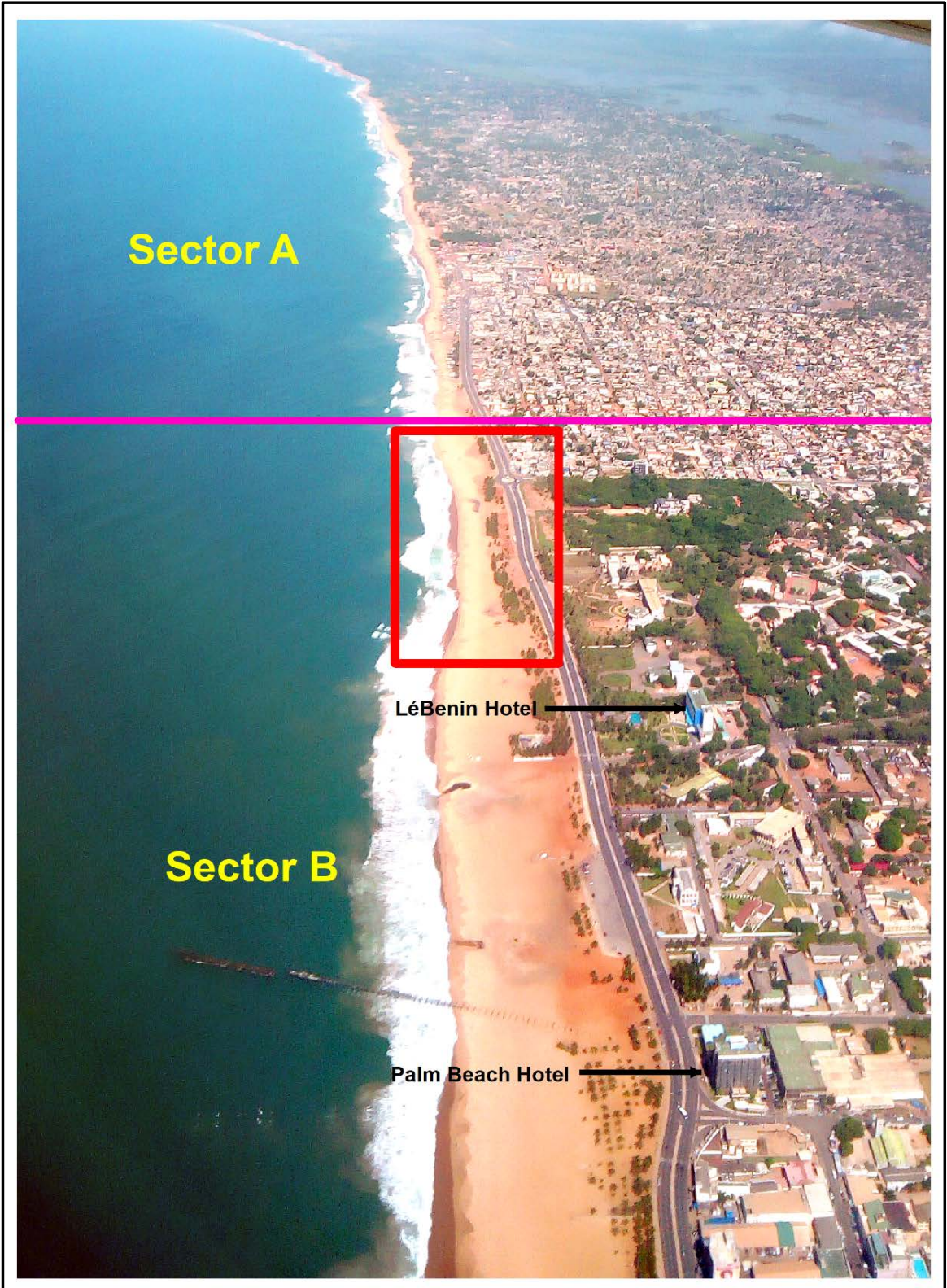

Figure 6. Aerial photograph acquired on January 2018 of the sectors A and B. (The erosion is very advanced and the sea is very close to the asphalt road in Sector A. For sector B, the erosion part is coloured in red).

For the kinematics of the shoreline, the southwest of the Togolese coast has an average erosion rate ranging from 2.49 to $5.07 \mathrm{~m} /$ year. The lowest rate is observed at Sector A towards Kodjoviakopé locality in Lomé city while the highest rate is observed at Sector $\mathrm{H}$ towards Kpogan locality. Although the lowest erosion rate is observed in sector $\mathrm{A}$, the erosion process is very advanced in this sector and the sea is near to the asphalt road. Appropriate measures of adaptations must be taken in this sector in particular and on the whole of the Togolese coast to avoid the immersion of the asphalt road by sea, displacement of populations and disturbance of human habitat. 


\section{Acknowledgements}

This research did not receive any specific grant from funding agencies in the public, commercial, or not-for-profit sectors. We thank as well the NGO APEDD-Togo that gave us their support for the field data collection. We thank also Mr. Bawinabadi Bagaram from Spatial Optimization Lab, School of Environmental and Forest Sciences, University of Washington for his contribution.

\section{Conflicts of Interest}

The authors declare no conflicts of interest regarding the publication of this paper.

\section{References}

[1] Deng, H.J., Chen, Y.N., Shi, X., Li, W.H., Wang, H.J., Zhang, S.H. and Fang, G.H. (2014) Dynamics of Temperature and Precipitation Extremes and Their Spatial Variation in the Arid Region of Northwest China. Atmospheric Research, 138, 346-355. https://doi.org/10.1016/j.atmosres.2013.12.001

[2] Konko, Y., Bagaram, B., Julien, F., Akpamou, K.G. and Kokou, K. (2018) Multitemporal Analysis of Coastal Erosion Based on Multisource Satellite Images in the South of the Mono Transboundary Biosphere Reserve in Togo (West Africa). Open Access Library Journal, 5, e4526. https://doi.org/10.4236/oalib.1104526

[3] Stanchev, H., Young, R. and Stancheva, M. (2013) Integrating GIS and High Resolution Orthophoto Images for the Development of a Geomorphic Shoreline Classification and Risk Assessment: A Case Study of Cliff/Bluff Erosion along the Bulgarian Coast. Journal of Coastal Conservation, 17, 719-728. https://doi.org/10.1007/s11852-013-0271-2

[4] Yang, B., Hwang, C. and Cordell, H.K. (2012) Use of LiDAR Shoreline Extraction for Analyzing Revetment Rock Beach Protection: A Case Study of Jekyll Island State Park, USA. Ocean \& Coastal Management, 69, $1 \mathrm{e} 15$. https://doi.org/10.1016/j.ocecoaman.2012.06.007

[5] Bayram, B., Seker, D.Z., Acar, U., Yuksel, Y., Guner, A.H.A. and Cetin, I. (2013) An Integrated Approach to Temporal Monitoring of the Shoreline and Basin of Terkos Lake. Journal of Coastal Research, 29, 1427-1435. https://doi.org/10.2112/JCOASTRES-D-12-00084.1

[6] Djagoua, E.M., Bakayoko, F., Kouadio, M.J., Kassi, A.J.B. and Mobio, A.B.H. (2016) Cartography of Coastal Dynamics in Grand-Lahou: Tool Use "Digital Shoreline Analysis System (Dsas)”. European Scientific Journal, 12, 327-335. https://doi.org/10.19044/esj.2016.v12n36p327

[7] Blivi, A. and Adjoussi, P. (2004) La cinématique du trait de côte du Togo vue par télédétection. Geo-Eco-Trop, 28, 27-38.

[8] Maiti, S. and Bhattacharya, A.K. (2009) Shoreline Change Analysis and Its Application to Prediction: A Remote Sensing and Statistics Based Approach. Marine Geology, 257, 11-23. https://doi.org/10.1016/j.margeo.2008.10.006

[9] Atsri, H.K., Konko, Y., Cuni-Sanchez, A., Abotsi, K.E. and Kokou, K. (2018) Changes in the West African Forest-Savanna Mosaic, Insights from Central Togo. PLoS ONE, 13, e0203999. https://doi.org/10.1371/journal.pone.0203999

[10] Konko, Y. (2016) Contribution of Remote Sensing and GIS to the Integrated Management of Community Forest Resources in the Bas-Mono Valley (South-East Togo). 
Master's Thesis, Post University Regional School of Integrated Management of Tropical Forests and Territories, Kinshasa, Democratic Republic of Congo. https://doi.org/10.13140/RG.2.2.20280.70403

[11] Kalkan, K., Bayram, B., Maktav, D. and Sunar, F. (2013) Comparison of SVM and Object Based Classification Methods for Shoreline Detection. ISPRS Conference on Serving Society with Geoinformatics, Antalya-Turkey. ISPRS International Archives of the Photogrammetry, Remote Sensing and Spatial Information Sciences, Volume XL-7/W2, 125-127. https://doi.org/10.5194/isprsarchives-XL-7-W2-125-2013

[12] Guariglia, A., Buonamassa, A., Losurdo, A., Saladino, R., Trivigno, M.L. and Zaccagnino, A. (2006) A Multisource Approach for Shoreline Mapping and Identification of the Shoreline Changes. Annals of Geophysics, 49, 295-304. http://www.cgiam.org/wp-content/uploads/2019/10/3155-3260-1-PB.pdf

[13] Pardo-Pascual, J.E., Almonacid-Caballer, J., Ruiz, L.A. and Palomar Vázquez, J. (2012) Automatic Extraction of Shorelines from Landsat TM and ETM+ Multi-Temporal Images with Subpixel Precision. Remote Sensing of Environment, 123, 1-11. https://doi.org/10.1016/j.rse.2012.02.024

[14] Demir, N., Oy, S., Erdem, F., Şeker, D.Z. and Bayram, B. (2017) Integrated Shoreline Extraction Approach with Use of Rasat MS and SENTINEL-1A SAR Images. ISPRS Annals of the Photogrammetry, Remote Sensing and Spatial Information Sciences, 4, 445. https://doi.org/10.5194/isprs-annals-IV-2-W4-445-2017

[15] Bayram, B., Avsar, E.Ö., Seker, D.Z., Kayi, A., Erdogan, M., Eker, O., Janpaule, I. and Çatal, R.H. (2017) The Role of National and International Geospatial Data Sources in Coastal Zone Management. Fresenius Environmental Bulletin, 26, 383-391.

[16] Wu, H., Liu, C., Zhang, Y. and Sun, W. (2009) Water Feature Extraction from Aerial-Image Fused with Airborne LIDAR Data. IEEE Urban Remote Sensing Event, Shanghai, 20-22 May 2009, 1-7.

[17] Yousef, A. and Iftekharuddin, K. (2014) Shoreline Extraction from the Fusion of LiDAR DEM Data and Aerial Images Using Mutual Information and Genetic Algorithms. 2014 International Joint Conference on Neural Networks (IJCNN), Beijing, 1007-1014. https://doi.org/10.1109/IJCNN.2014.6889863

[18] UNESCO (2017) Biosphere Reserves. http://www.unesco.org/mab

[19] Konko, Y., Rudant, J.P., Akpamou, G.K., Noumonvi, K.D. and Kokou, K. (2018) Spatio-Temporal Distribution of Southeastern Community Forests in Togo (West Africa). Journal of Geoscience and Environment Protection, 6, 51-65. https://doi.org/10.4236/gep.2018.67004

[20] Nimon, P., Issaou, L., Konko, Y. and Kokou, K. (2020) Spatio-Temporal Patterns of Rainfall Variability for Wet Season over Togo in West Africa. Open Access Library Journal, 7, e6044. https://doi.org/10.4236/oalib.1106044

[21] Wang, X., Liu, Y., Ling, F., Liu, Y. and Fang, F. (2017) Spatio-Temporal Change Detection of Ningbo Shoreline Using Landsat Time-Series Images during 1976-2015. International Journal of Geo-Information, 6, 68. https://doi.org/10.3390/ijgi6030068

[22] Mcfeeters, S.K. (1996) The Use of the Normalized Difference Water Index (NDWI) in the Delineation of Open Water Features. International Journal of Remote Sensing, 17, 1425-1432. https://doi.org/10.1080/01431169608948714

[23] Mas, J.F. (1999) Monitoring Land-Cover Changes: A Comparison of Change Detection Techniques. International Journal of Remote Sensing, 20, 139-152. https://doi.org/10.1080/014311699213659

[24] Frazier, P.S. and Page, K.J. (2000) Water Body Detection and Delineation with Landsat TM Data. Photogrammetric Engineering and Remote Sensing, 66, 1461-1467. http://web.pdx.edu/ nauna/resources/5-2000_dec_1461-1467.pdf 
[25] Burningham, H. and French, J. (2017) Understanding Coastal Change Using Shoreline Trend Analysis Supported by Cluster-Based Segmentation. Geomorphology, 282, 131-149. https://doi.org/10.1016/j.geomorph.2016.12.029

[26] Liu, H. and Jezek, K.C. (2004) Automated Extraction of Shoreline from Satellite Imagery by Integrating Canny Edge Detection and Locally Adaptive Thresholding Methods. International Journal of Remote Sensing, 25, 937-958.

https://doi.org/10.1080/0143116031000139890

[27] Otsu, N. (1975) A Threshold Selection Method from Gray-Level Histograms. Automatica, 11, 23-27.

http://webserver2.tecgraf.puc-rio.br/ mgattass/cg/trbImg/Otsu.pdf

[28] Li, W., Du, Z., Ling, F., Zhou, D., Wang, H., Gui, Y., Sun, B. and Zhang, X.A. (2013) Comparison of Land Surface Water Mapping Using the Normalized Difference Water Index from TM, ETM+ and ALI. Remote Sensing, 5, 5530-5549. https://doi.org/10.3390/rs5115530

[29] Du, Z., Li, W., Zhou, D., Tian, L., Ling, F., Wang, H., Gui, Y. and Sun, B. (2014) Analysis of Landsat-8 OLI Imagery for Land Surface Water Mapping. Remote Sensing Letter, 5, 672-681. https://doi.org/10.1080/2150704X.2014.960606

[30] Du, Y., Zhang, Y., Ling, F., Wang, Q., Li, W. and Li, X. (2016) Water Bodies' Mapping from Sentinel-2 Imagery with Modified Normalized Difference Water Index at 10-m Spatial Resolution Produced by Sharpening the SWIR Band. Remote Sensing, 8, 354. https://doi.org/10.3390/rs8040354

[31] Stanchev, H., Stancheva, M., Young, R. and Palazov, A. (2017) Analysis of Shoreline Changes and Cliff Retreat to Support Marine Spatial Planning in Shabla Municipality, Northeast Bulgaria. Ocean \& Coastal Management, 156, 127-140. https://doi.org/10.1016/j.ocecoaman.2017.06.011

[32] Sezgin, M. and Sankur, B. (2004) Survey over Image Thresholding Techniques and Quantitative Performance Evaluation. Journal of Electronic Imaging, 13, 146-165. https://doi.org/10.1117/1.1631315

[33] Kuleli, T., Guneroglu, A., Karsli, F. and Dihkan, M. (2011) Automatic Detection of Shoreline Change on Coastal Ramsar Wetlands of Turkey. Ocean Engineering, 38, 1141-1149. https://doi.org/10.1016/j.oceaneng.2011.05.006

[34] Ball, G.H. and Hall, D.J. (1965) ISODATA, a Novel Method of Data Analysis and Pattern Classification. Stanford Research Inst., Menlo Park. https://apps.dtic.mil/dtic/tr/fulltext/u2/699616.pdf

[35] Venkateswarlu, N.B. and Raju, P.S.V.S.K. (1992) Fast ISODATA Clustering Algorithms. Pattern Recognition, 25, 335-342. https://doi.org/10.1016/0031-3203(92)90114-X

[36] Mantero, P., Moser, G. and Serpico, S.B. (2005) Partially Supervised Classification of Remote Sensing Images through SVM-Based Probability Density Estimation. IEEE Transactions on Geoscience and Remote Sensing, 43, 559-570. https://doi.org/10.1109/TGRS.2004.842022

[37] Vapnik, V. (1982) Estimation of Dependences Based on Empirical Data. Nauka, Moscow, 5165-5184, 27.

[38] Himmelstoss, E.A., Henderson, R.E., Kratzmann, M.G. and Farris, A.S. (2018) Digital Shoreline Analysis System (DSAS) Version 5.0 User Guide: U.S. Geological Survey Open-File Report 2018-1179, 110 p. https://doi.org/10.3133/ofr20181179

[39] Crowell, M., Douglas, B.C. and Leatherman, S.P. (1997) On Forecasting Future U.S. Shoreline Positions: A Test of Algorithms. Journal of Coastal Research, 13, 1245-1255. https://pdfs.semanticscholar.org/487a/f1d339113d96669ac08661b37ba92824dc52.pdf 
[40] Thieler, E.R., Himmelstoss, E.A., Zichichi, J.L. and Ergul, A. (2017) Digital Shoreline Analysis System (DSAS) Version 4.0, an ArcGIS Extension for Calculating Shoreline Change. US Geological Survey Open-File Report 2008-1278. https://doi.org/10.3133/ofr20081278

[41] Noumonvi, K.D., Mounir, F. and Belghazi, B. (2017) Spatial Multi-Criteria Based Analysis to Assess Dynamics and Vulnerability of Forest Ecosystems to Global Changes: Case of Maamora Forest-Morocco. Open Access Library Journal, 4, e3889. https://doi.org/10.4236/oalib.1103889 